\title{
CERVEJA \\ OU VÍRUS? \\ O OBJETO \\ DE DISCURSO \\ CORONA \\ EM MEMES \\ FOTOGRÁFICOS \\ DA INTERNET
}

\section{¿CERVEZA O VIRUS? EL OBJETO DE DISCURSO CORONA EN MEMES FOTOGRÁFICOS DE INTERNET}

\section{BEER OR VIRUS? THE CORONA SPEECH OBJECT IN PHOTOGRAPHIC MEMES OF THE}

INTERNET

Wagner Alexandre dos Santos Costa*

Universidade Federal Rural do Rio de Janeiro

RESUMO: Analisa-se, neste artigo, um corpus de dez memes fotográficos elaborados a partir da relação entre dois conteúdos: coronavírus/Covid-19 e cerveja Corona Extra. Com base no conceito de Referenciação, conforme Mondada (1994, 2002, 2008), Marcuschi e Koch (2002) e Marcuschi (2004, 2007), entre outros autores, entendendo que os objetos de discurso podem ser ativados e/ou reativados tanto por procedimentos textuais-discursivos quanto por cognitivo-inferenciais, o estudo objetiva evidenciar como é feita essa relação e quais sentidos são construídos a partir dela. Os memes foram produzidos em período simultâneo ao da propagação do coronavírus pelo mundo, entre dezembro de 2019 e (até o momento) abril de 2020.

PALAVRAS-CHAVE: Memes. Referenciação. Coronavírus.

RESUMEN: En este artículo, se analiza un corpus de diez memes fotográficos elaborados a partir de la relación entre dos contenidos: coronavirus / Covid-19 y cerveza Corona Extra. Basado en el concepto de referencia, según Mondada (1994, 2002, 2008), Marcuschi

\footnotetext{
* Doutor em Estudos da Linguagem pela Universidade Federal Fluminense (UFF) e docente do Departamento de Letras e Comunicação da Universidade Federal Rural do Rio de Janeiro (DLC/UFRRJ) e do Mestrado Profissional em Letras (PROFLETRAS/UFRRJ).E-mail: wagnercosta.prof@gmail.com
} 
y Koch (2002) y Marcuschi $(2004,2007)$, entre otros autores, entendiendo que los objetos de discurso pueden ser activados y / o reactivados tanto por procedimientos textual-discursivos y cognitivos-inferenciales, el estudio tiene como objetivo mostrar cómo se hace esta relación y qué significados se construyen a partir de ella. Los memes se produjeron simultáneamente con la propagación del coronavirus en todo el mundo, entre diciembre de 2019 y (hasta ahora) abril de 2020.

PALABRAS CLAVE: Memes. Referencias. Coronavirus.

ABSTRACT: In this article, a corpus of ten photographic memes elaborated based on the relationship between two contents: coronavirus / Covid-19 and Corona Extra beer is analyzed. Based on the concept of Referencing, according to Mondada (1994, 2002, 2008), Marcuschi and Koch (2002) and Marcuschi (2004, 2007), among other authors, understanding that speech objects can be activated and / or reactivated both by textual-discursive and cognitive-inferential procedures, the study aims to show how this relationship is made and which meanings are constructed from it. The memes were produced simultaneously with the spread of the coronavirus around the world, between December 2019 and (so far) April 2020.

KEYWORDS: Memes. Referencing. Coronavirus.

\section{INTRODUÇÃO}

A partir de dezembro de 2019, na China, propagam-se casos de uma doença denominada Covid-19, decorrentes de contaminação por um novo tipo de coronavírus, o SARS-CoV-2. O nome dessa família de vírus deve-se a suas características morfológicas semelhantes a uma coroa. O vírus se espalha por todos os continentes, atingindo, até a data de 15 de abril de 2020, mais de 2.000.000 (dois milhões) de pessoas em todo o mundo, com aproximadamente 200.000 (duzentas mil) mortes. Só no Brasil, conforme dados da Organização Pan-Americana de Saúde (OPAS, 2020), a partir da confirmação oficial do primeiro caso, em 26 de fevereiro de 2020, são aproximadamente 30.000 (trinta mil) casos de infecção, dos quais decorreram quase 1.800 (mil e oitocentas) mortes, até a data de 15 de abril, às 19 horas, data e hora deste registro.

Em várias partes do mundo, surgem associações entre a marca de cerveja mexicana Corona Extra e a propagação do vírus (FOLHA DE SÃO PAULO, 2020). Em relação ao Brasil, no mês de janeiro, a ferramenta de verificação de buscas Google Trends registra elevação nas pesquisas em torno do nome coronavírus feitas em associação com a cerveja Corona (GOOGLE TRENDS, 2020). Verificando o termo de pesquisa "cerveja corona vírus", tal como criado pelos usuários, observa-se que entre 26 de janeiro e $1^{\circ}$ de fevereiro foram realizadas 37 buscas. Já entre 15 e 21 de março esse número aumenta consideravelmente, totalizando 100 buscas feitas para este período.

Por desconhecimento da apenas coincidência entre nomes ou por intenção de produzir determinado tipo de humor, vários memes viralizaram na Internet, nos quais também essa associação foi estabelecida. Com isso, foram compartilhadas ideias negativas sobre a cerveja, conforme várias fontes.

Em pesquisa divulgada pela agência estadunidense YouGov, realizada entre os meses de janeiro e fevereiro, os consumidores do país reduziram consideravelmente a intenção de consumo da cerveja Corona (YOU GOV, 2020). Trata-se de um exemplo flagrante de como a linguagem, simbólica que é, pode provocar alterações no mundo real.

O objetivo deste estudo é, então, analisar um corpus de dez memes de Internet que apresentam como conteúdo a relação entre a pandemia de coronavírus/Covid-19 e a cerveja Corona Extra. Pretende-se evidenciar como é feita essa relação e quais sentidos são construídos a partir dela. O período de produção desses memes dá-se simultaneamente ao da propagação do vírus pelo mundo, entre dezembro de 2019 e (até o momento) abril de 2020. Os textos foram capturados do Google images (2019-2020) no mesmo período.

A ótica teórica pela qual são observadas as ocorrências é a dos processos de referenciação (MONDADA, 1994, 2002, 2008; MARCUSCHI; KOCH, 2002; MARCUSCHI, 2004, 2007), entendendo que os objetos de discurso podem ser ativados e/ou reativados tanto por procedimentos textuais-discursivos quanto por cognitivo-inferenciais. Além disso, assumimos a posição de que, a partir da realidade cada vez mais multimodal dos textos, como no caso dos memes, os processos de referenciação envolvem, 
em muitos casos, a integração entre mais de um tipo de semiose, exigindo que na atividade de interpretação os sujeitos realizem o que Mondada (1994) entende por cognição distribuída.

Inicialmente, são apresentadas as bases teóricas do estudo, que se inserem no campo de estudos da Linguística Textual, especificamente na Teoria da Referenciação. No contínuo, a partir de estudos da área da Comunicação, conceitua-se o gênero discursivo meme e mostra-se a tipificação dos memes fotográficos para, em seguida, após explicitação dos procedimentos metodológicos, proceder-se à análise das ocorrências.

\section{REFERENCIAÇÃO E MULTIMODALIDADE}

Neste estudo tem-se como ponto de partida a assunção de que, por meio da atividade de referenciação, os falantes instauram e compartilham sentidos no evento de comunicação. Especificamente, "os sujeitos constroem, através de práticas discursivas e cognitivas social e culturalmente situadas, versões públicas do mundo” (MONDADA; DUBOIS, 2003 [1995], p. 17).

Como explica Mondada (1994), a noção de objetos de discurso refere-se ao que a atividade enunciativa organiza nas práticas de apreensão, formulação e descrição do mundo pelos falantes. São recursos pelos quais os usuários discursivizam o mundo, sendo desenvolvidos e modificados conforme o contexto. Não são preexistentes, nem são já dados, convencionais ou fixos. Em acordo com essa compreensão, o conceito de referenciação concerne às atividades enunciativas construídas intersubjetivamente pelos falantes.

Apothéloz e Reichler-Béguelin (1995), assumindo como Mondada (1994) a propriedade dinâmica dos objetos de discurso, entenderam que a atividade anafórica de retomada de um item lexical pode não apenas servir como mero processo de substituição na linearidade textual, mas pode ainda constituir-se num procedimento de acréscimo informacional. Nesse sentido, lançaram bases para o entendimento do processo de recategorização, no entanto ainda como uma concepção textual-discursiva, uma vez que concebiam os limites da superfície textual na construção de cadeias textuais serem o espaço de surgimento do fenômeno.

Outros autores (MONDADA, 1994, 2002, 2008; MARCUSCHI; KOCH, 2002; MARCUSCHI, 2004, 2007) desenvolveram estudos de acordo com os quais os processos de referenciação podem ocorrer com base em ativação mental de informações, sem menção propriamente dita no texto. Avança-se, então, a uma concepção cognitivo-discursiva dessa atividade. Além disso, a percepção de que diferentes recursos semióticos (palavra, imagem, som, gestos etc.) são também empregados no desenvolvimento da comunicação, e muitas vezes articulados entre si, acrescentou a tal visão a compreensão de que a multimodalidade é um modo complexo de significar do qual participam as operações de referenciação.

Nessa perspectiva, diferentes estudos foram realizados (MONDADA, 1994, 2002, 2008; BRASSAC et al., 2008) acerca da atividade de interação em contextos profissionais e científicos, mostrando que os sentidos podem ser construídos coletivamente com o auxílio de vários recursos multimodais. Assim, em uma atividade cognitivamente distribuída, ou seja, por meio de gestos, olhares, movimentos corporais, com o auxílio de instrumentos/objetos, o saber é elaborado de maneira indissociável (necessariamente articulado) por meio de artefatos escritos e visuais.

Apresenta-se, nessas pesquisas, uma visão multimodal de referenciação, afrouxando-se, dessa maneira, uma concepção restrita dos processos de referenciação apenas na linearidade do texto verbal. Com isso, abre-se um campo para a observação de outras linguagens e seus mecanismos discursivos.

No campo da Semiótica social, por exemplo, o trabalho de Kress e van Leeuween (2006) sobre multimodalidade destaca a importância de se considerar os diferentes modos pelos quais a linguagem (portanto, a comunicação) pode se constituir (palavras, sons, imagens etc.): "Intencionamos fornecer descrições das principais estruturas composicionais, que se estabelecem como convenções no curso da história ocidental da semiótica visual e analisar como elas estão para produzir sentidos pelos produtores de imagens" (KRESS; van LEEUWEN, 2006 [1996], p. 1). 
Propõem, na obra, descrever diversas estruturas composicionais e desenvolver uma abordagem horizontal da relação entre palavra e imagem, sem uma supremacia do texto verbal sobre o não verbal. Os autores advogam, então, por uma construção integradora de sentidos.

As práticas urbanas de interação, intensamente mediadas por recursos digitais e formadas por grupos com vivências culturais variadas, exigem que se reclame uma atenção especial ao modo como são constituídos textos e construídos sentidos. Assim, a multimodalidade refere-se, conforme Rojo (2012, p. 18-19), à multiplicidade de linguagens nos textos: "sejam impressos ou digitais [...] as imagens e o arranjo de diagramação impregnam e fazem significar os textos contemporâneos”.

Tudo isso exerce impacto na vida social dos cidadãos e vai moldando suas necessidades de (multi)letramentos para a vida na sociedade. Segundo Rojo (2012, p.13)

O conceito de multiletramentos aponta para dois tipos específicos e importantes de multiplicidade presentes em nossas sociedades, principalmente as urbanas, na contemporaneidade: a multiplicidade cultural das populações e a multiplicidade semiótica de constituições dos textos por meio dos quais ela se informa e se comunica.

Isto significa que as práticas sociais, com frequência cada vez maior de semioses variadas na construção dos textos, reclamam habilidades de leitura para além daquelas ligadas à linearidade do texto verbal. É o caso dos memes que, por sua natureza multimodal, exigem considerar o papel de cada material (e o que a partir dele é evocado) na construção dos sentidos.

\section{MEMES FOTOGRÁFICOS}

O termo meme, cunhado na década de 70 por Dawkins (2007[1976]), denominava uma unidade de replicação cultural análoga ao gene. Segundo o autor, os conteúdos culturais propagam-se nas mentes das pessoas, onde se modificam e evoluem. Na atualidade, o termo designa um determinado molde textual, caracterizado por sua funcionalidade em um contexto sócio-comunicacional.

Shifman (2014, p. 341) define memes de Internet como um agrupamento de textos digitais que: "(a) compartilham características comuns de conteúdo, forma e / ou postura; (b) são criados com consciência um do outro; e (c) são circulados, imitados e transformados pela Internet por vários usuários”.

Na conceituação de Oliveira (2017, p. 1),

[...] o meme é uma forma digital (áudio) visual e/ou textual que é apropriada e recodificada pelos usuários, sendo introduzidas de volta na infraestrutura da Internet de onde vieram (NOONEY; PORTWOOD-STACER, 2014, p. 249). Ou seja, trata-se de um "molde comum" ou "modelo formal básico" (FONTANELLA, 2009, p. 09) que é rapidamente assimilado, copiado e repetido, gerando diversas versões e variações do meme que se espalham de pessoa a pessoa de maneira viral.

Em nosso entendimento, trata-se de um gênero discursivo de ambiência digital caracterizado pela replicabilidade veloz de unidades de sentido (por exemplo, uma cena, uma frase, uma fotografia), atualizadas discursivamente em cada enunciação. Possui, em geral, hibridez composicional, o que significa, por sua natureza, ser constituído de uma ou mais semioses (palavra, imagem, som, gifs, vídeo). Do ponto de vista de sua funcionalidade, admite o humor, a crítica, ou imprevisivelmente, outras funções. Além disso, são textos necessariamente compartilháveis, o que os leva a constituírem uma rede de enunciados interligados entre si, ao passo que também agrupam pessoas com interesses comuns.

Shifman (2014) desenvolve, ainda, o conceito de hipersignificação em relação aos memes fotográficos. Explica que, nos memes, como na publicidade, as fotografias operam uma desconstrução da realidade. Muitas vezes, adicionalmente, nessas formas textuais, deixase evidenciar a própria atividade da construção, o que assume uma significação não apenas relativa ao conteúdo, mas pode carrear ironia, humor, denunciar ou reforçar preconceitos etc. 
Vários estudos apresentam diferentes propostas de categorização dos memes. Lima (2014) propõe uma classificação semântica dos memes de Facebook; Recuero (2007) desenvolve uma taxionomia dos memes para weblogs; Chagas (2018) traz uma classificação formal dos memes fotográficos. Adotando este último, temos a seguinte tipificação:

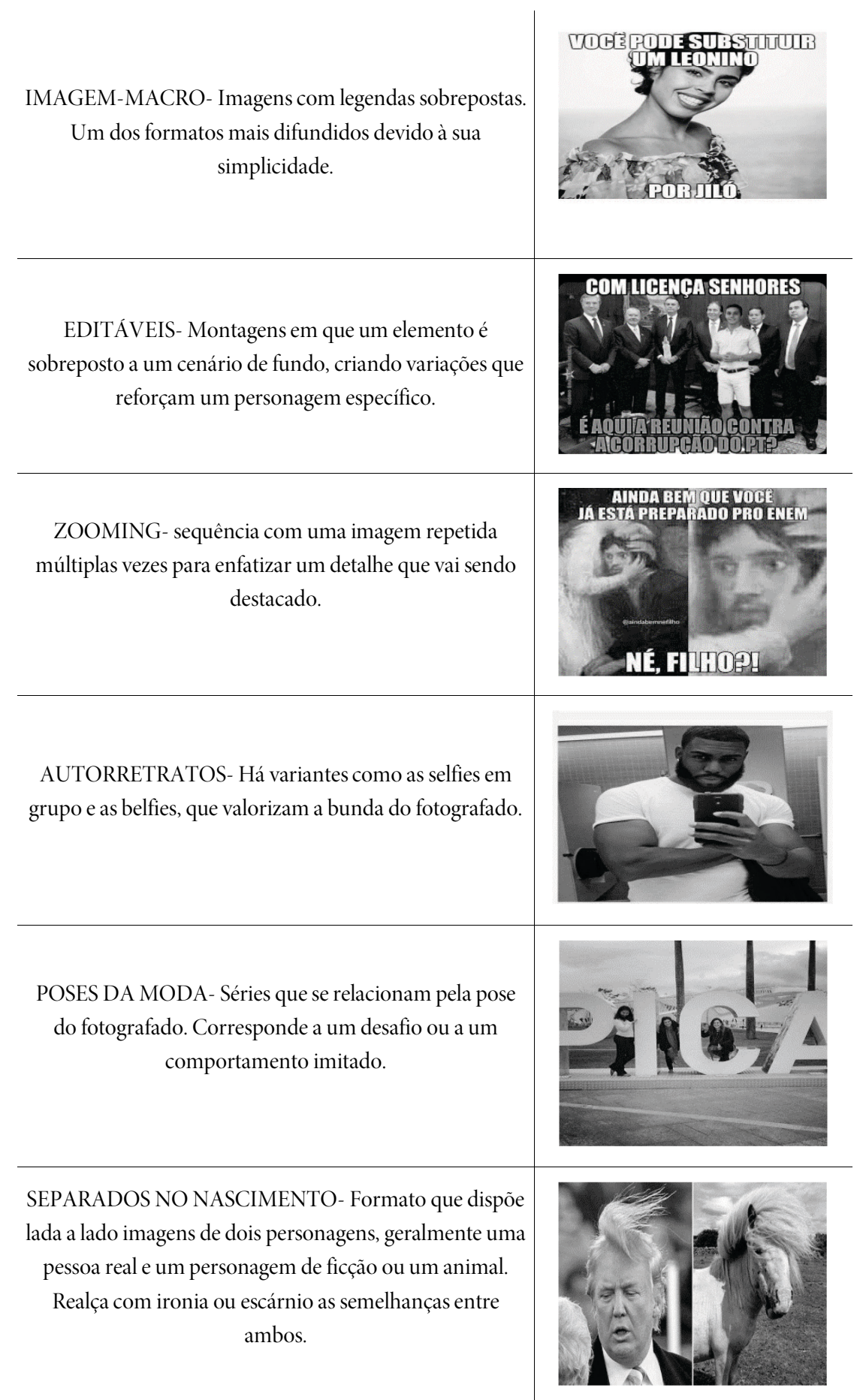

Quadro 1: Memes fotográficos

Fonte: elaborado pelo autor a partir do Google Images (2020)

Na abordagem de Chagas (2018), ressalta-se, em geral, a manipulação formal das semioses envolvidas na elaboração do meme. Importa observar que esses são recursos de construção de sentido que caracterizam a modalidade da linguagem dos memes, que ultrapassa a oralidade ou a escrita, pois é multimodal. 
O memes elaborados com emprego de legendas se destacam por sua alta voltagem, relacionada aos usuários poderem operar a replicação da semiose de base (em geral uma foto, uma fotomontagem etc.) e acrescentar legenda, criando outro enunciado na totalidade verbal-imagética. Isto é mais recorrente nos tipos imagem-macro, editáveis e zooming. Paralelamente, as técnicas da fotomontagem, fotolegenda, zooming constituem também recursos de significação que podem se integrar ou não a legendagem do meme.

Os autorretratos e poses da moda se diferem dos anteriores pela natureza mais situada dos enunciados. Por exemplo, na rede de memes da Bela Gil, há uma integração entre os enunciados criados pelos usuários, qual seja a forma delicada com que a apresentadora de programa culinário sugere aos seus espectadores substituir um ingrediente por outro mais saudável. Um tradicional Você pode substituir carne por linhaça, por exemplo gerou memes legendados como Vocêpode substituir Alckmin por inhame, por exemplo. Vejase:

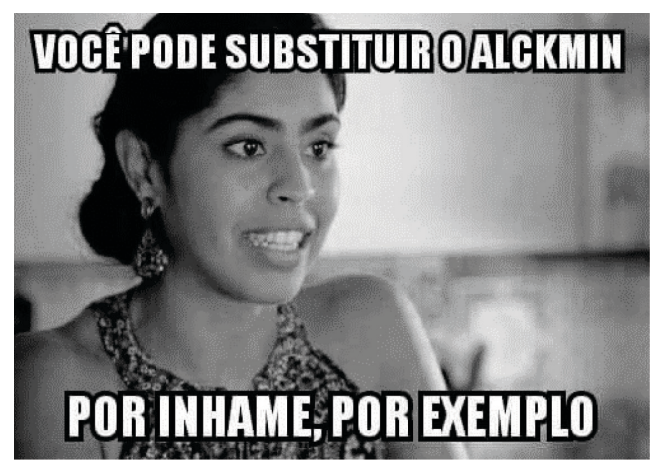

Imagem 1: Meme Bela Gil

Fonte: Google Images (2019)

Não é o que ocorre exatamente na difusão dos tipos autorretratos e poses da moda. Esses memes dialogam principalmente pela sua organização estrutural, que é a pose ou o local.

Nos memes do tipo separados no nascimento, a construção de sentidos, em geral pejorativos, é alcançada pela associação entre as imagens, dispensando quase sempre a legendagem. Nesses casos, o conteúdo dos memes extrapola a mera associação fisionômica entre os personagens, pois eles hipersignificam (SHIFMAN, 2014), geralmente atribuindo conteúdo político-ideológico ou veiculando preconceitos vários.

Tendo exposto a fundamentação teórica que embasa o estudo, passamos, a seguir, à análise do corpus. Antes, descreveremos a metodologia de pesquisa adotada.

\section{PROCEDIMENTOS METODOLÓGICOS}

O corpus em análise é constituído de dez memes fotográficos coletados entre dezembro/2019 e abril/2020. Todos os memes, ao final do período de coleta, estavam ainda disponíveis ao acesso. Para gerar os dados, foi feita uma busca no Google imagem com o termo "memes cerveja corona". A unidade dos textos se caracteriza pela relação entre os conteúdos coronavírus/Covid-19 e cerveja Corona, o que se constituiu em critério de seleção.

A forma de tratamento dos dados é qualitativa e a análise objetiva evidenciar a) como é feita essa relação entre os conteúdos coronavírus/Covid-19 e cerveja Corona e b) quais sentidos são construídos a partir dessa relação. Assim, nossa observação recai especificamente sobre

\footnotetext{
$\checkmark \quad$ a ativação do referente corona (imagético ou verbal) e sua integração a outros elementos textuais;

$\checkmark \quad$ como se dá a atividade inferencial de referenciação na relação entre os conteúdos;
} 
o processo de (re)construção de sentidos da marca Corona Extra.

\section{CORONA: (RE)CONSTRUÇÃO DE SENTIDOS EM MEMES FOTOGRÁFICOS}

O conjunto dos dez memes coletados para este estudo propõe, do ponto de vista da funcionalidade, gerar a produção de humor a partir de sua circulação entre usuários de redes sociais, como Facebook e Instagram, e aplicativos como whatsapp.

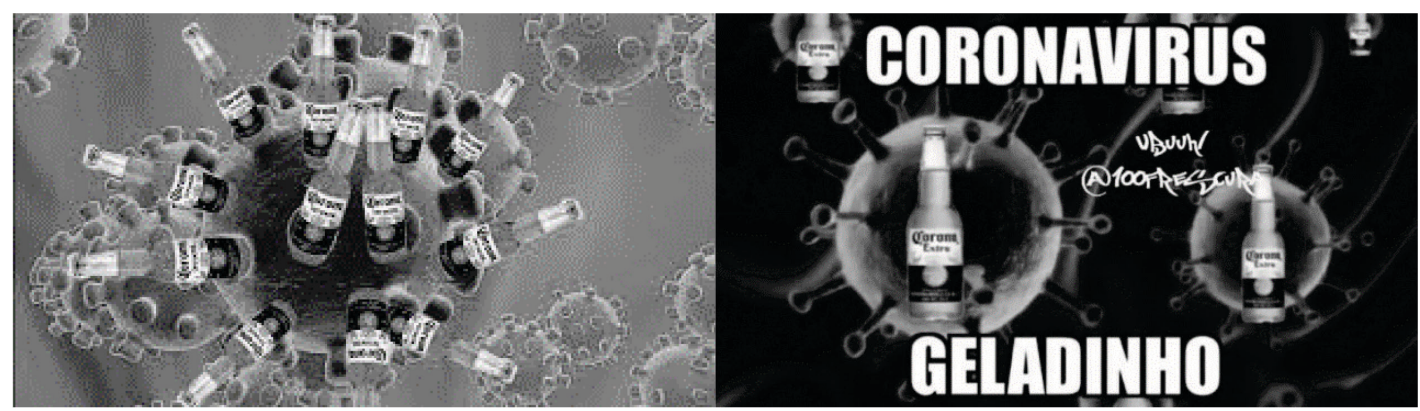

Imagem 2: Meme (2)

Imagem 3: Meme (3)

Fonte: Google Images (2020)

Os memes (2) e (3) são do tipo editáveis, construídos pela sobreposição da imagem da cerveja Corona a imagens do vírus ao fundo. Em (2), é a morfologia do vírus em forma de coroa que se destaca. A sua parte denominada glicoproteína é representada pelas garrafas de cerveja. Em (3), a imagem da cerveja surge no interior do vírus, como que a representar o RNA (seu material genético).

Em (2), não há legendagem, a construção de sentidos se estabelece pela relação entre as imagens. Temos, então, ativados os dois objetos de discurso em jogo: Corona e coronavírus, a partir dos quais entrelaçam-se os conteúdos. Em (3), o que a legendagem faz é tornar mais explícito o estabelecimento da relação, e, por conseguinte, o seu propósito. Depreende-se desse jogo a interpretação de que a cerveja é o vírus "geladinho".

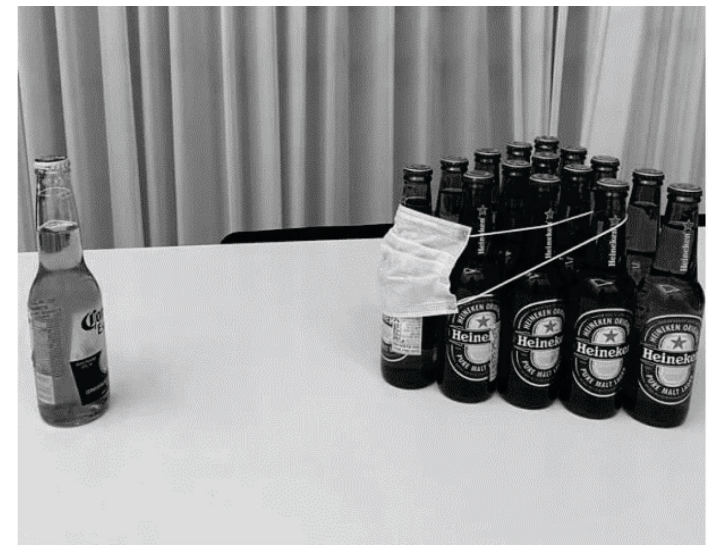

Imagem 4: Meme (4)

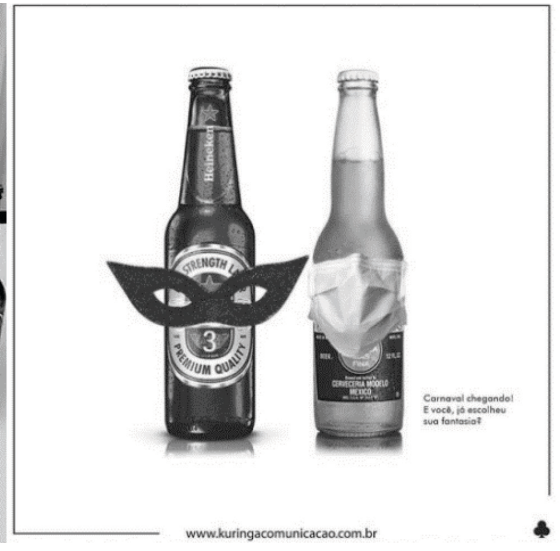

Imagem 5: Meme (5)

Fonte: Google Images (2020)

O meme (4) é do tipo imagem-macro; já o meme (5), editável. Nos dois casos, a associação entre Corona e coronavírus dá-se pela ativação explícita (textual-discursiva) do objeto de discurso máscara, que permite, indiretamente, a ativação por procedimento inferencial (cognitivo-discursiva) do objeto de discurso coronavírus, ainda que este não seja mencionado imagética e verbalmente.

${ }^{1}$ No texto verbal: "Carnaval chegando! E você, já escolheu sua fantasia?" 
Em (4), considerada a ativação do objeto de discurso coronavírus, a imagem da cerveja Corona, por procedimento metafórico de referenciação, passa a significar o próprio vírus, ou seja, a marca da contaminação. Por isso, opostamente, põe-se um conjunto de indivíduos representados pela marca concorrente Heineken, para representação da coletividade saudável a ser protegida.

Em (5), semelhantemente, opõem-se dois tipos de sentido qualificativo: um eufórico, para Heineken; outro disfórico, para Corona, sentidos associados à frase de efeito Carnaval chegando! E você, já escolheu sua fantasia?. Observe-se que esses sentidos são arrolados via ativação imagética (portanto, textual-discursiva) dos objetos de discurso máscara de carnaval e máscara de proteção, respectivamente qualificadores das cervejas Heineken e Corona.

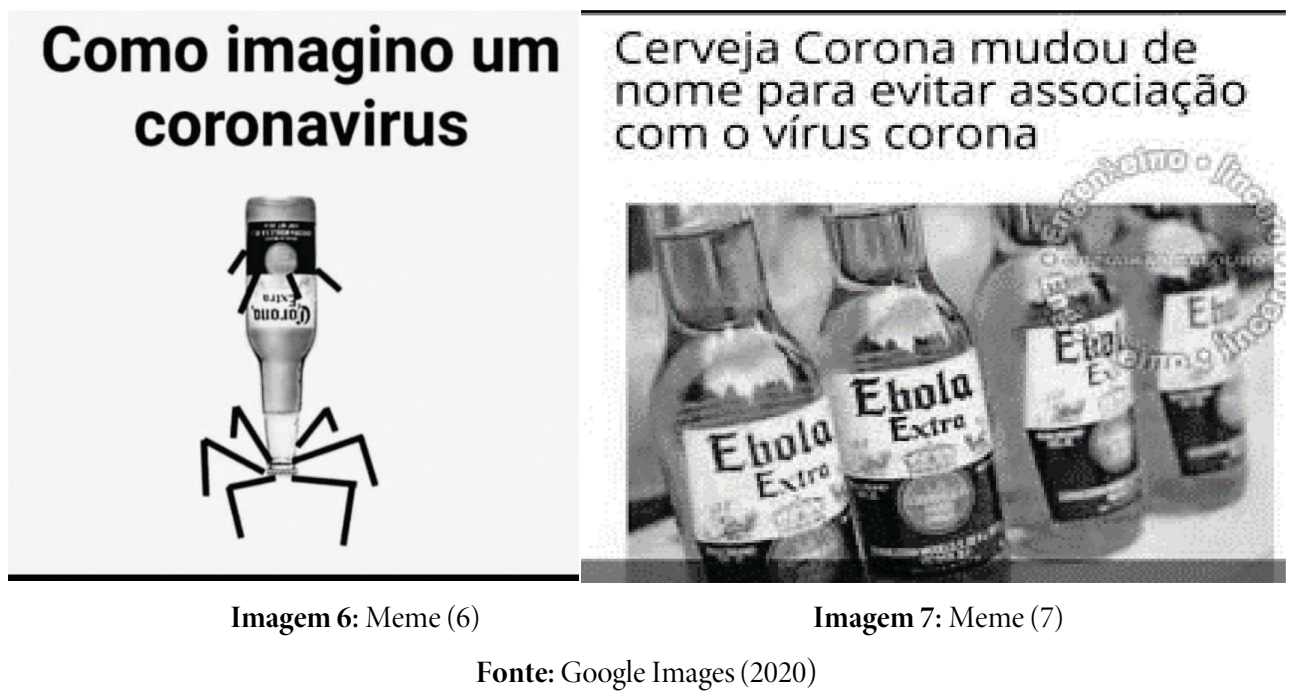

Os memes (6) e (7) são do tipo editáveis, pois em (6) a imagem da cerveja é modificada pela inclusão de elementos que tentam reproduzir a imagem de um vírus. Já em (6), é a edição do rótulo que possibilita enquadrar esse meme como editável, uma vez que há substituição do nome Corona pelo nome Ebola².

Em (6), a legenda Como imagino um coronavírus é prospectiva, projetando-se para a imagem situada abaixo. O objeto de discurso coronavírus é ativado tanto verbal quanto imageticamente (procedimento textual-discursivo), a diferença na referenciação imagética é que ela se constitui centralmente pela imagem da cerveja Corona, o que, por consequência, sintetiza e expõe a relação de sentido pretendida.

Em (7), a edição se localiza no rótulo com a ativação do objeto de discurso Ebola, que nomeia e recategoriza a cerveja na imagem. Ainda que não houvesse a legenda Cerveja Corona mudou de nome para evitar associação com o vírus corona, o objeto de discurso Corona estaria presentificado no texto, ativado inferencialmente, por exemplo, pela semelhança imagética da garrafa, cor do líquido, grafismo das letras e cor do rótulo, além do próprio logotipo da marca Corona. No entanto, na adição da legenda ao texto, em uma tentativa de explicitar a proposta de humor do meme, os objetos de discurso Corona e coronavírus são já ativados. A quebra da expectativa, mote para produção do humor, é justamente a antítese provocada pela edição do rótulo com o nome Ebola, vírus também altamente perigoso. Assim, é a partir dessa edição que a relação entre os conteúdos Corona e coronavírus se estabelece. O leitor opera com vários procedimentos simultâneos de referenciação, construindo sentidos por meio de uma cognição distribuída.

${ }^{2}$ Referência a uma doença altamente infecciosa surgida no continente africano e que também é transmitida por vírus. 


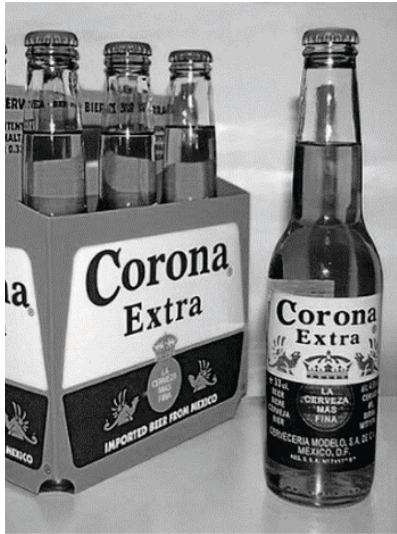

Imagem 8: Meme (8)

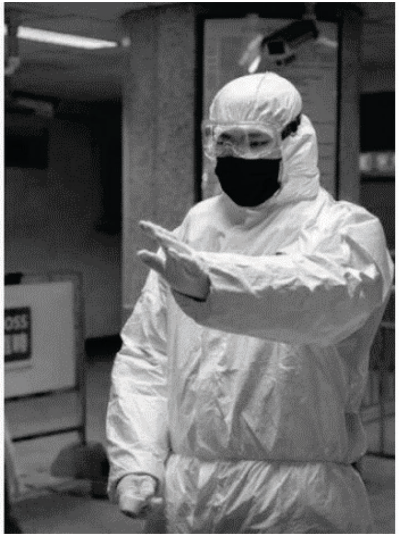

Fonte: Google Images (2020)

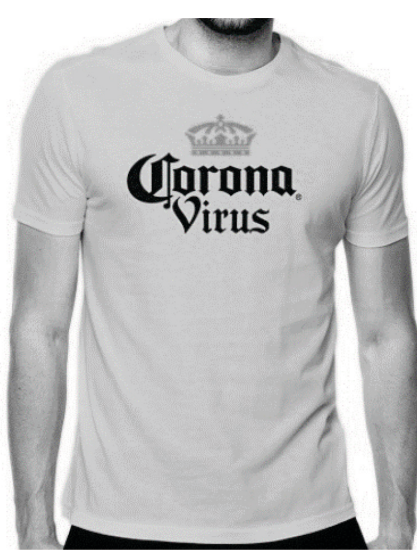

Imagem 9: Meme (9)

O meme (8) é do tipo imagem-macro em dois quadros e sem sobreposição de legenda. Já o meme (9) é do tipo editável, com a sobreposição do logotipo da marca e do nome da cerveja Corona à camisa amarela (procedimento copia-cola). Em acréscimo, insere-se a palavra vírus para formar o nome Corona Vírus.

Em (8), se considerarmos cada quadro isoladamente, não se torna possível a ativação do objeto de discurso coronavírus, o que advém apenas da integração dos dois elementos da estrutura. No primeiro quadro, ativa-se verbal e imageticamente o objeto de discurso Corona apenas. É o elemento visual do segundo quadro (o homem com máscara, luvas e roupa de proteção, gestualizando distância para um ponto de referência onde se localiza a cerveja) que exige o procedimento de reconstrução dos sentidos atribuídos ainda parcialmente ao todo discursivo do meme. Então, inferencialmente, o objeto de discurso coronavírus é ativado e, consequentemente, estabelecida a relação entre os conteúdos Corona e coronavírus.

No meme (9), como foi dito, são associados os dois conteúdos, Corona e coronavírus, pela ativação do objeto de discurso Corona Virus em um mesmo estilismo de letras e com a coroa, logotipo da marca. O fundo amarelo pode, ainda, aludir à cor da bebida, ao sol (coroa solar, por extensão: verão, praia) a que o nome da cerveja faz menção.

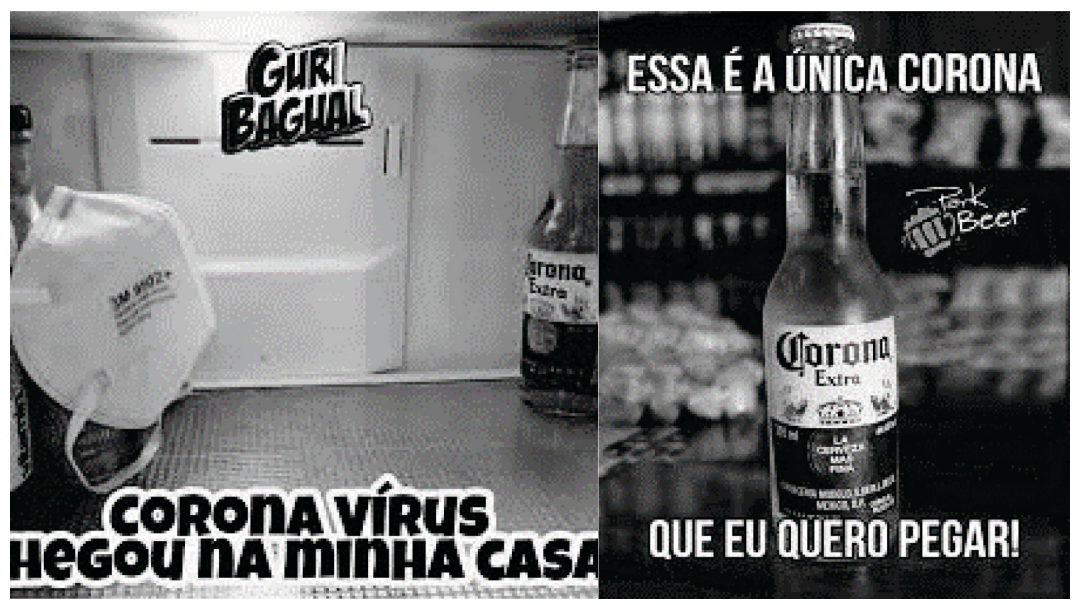

Imagem 10: Meme (10)

Imagem 11: Meme(11)

Fonte: Google Images (2020)

Os memes (10) e (11) são do tipo imagem-macro com sobreposição de legenda, construção mais comum pela menor exigência de elaboração. 
Em (10), o objeto de discurso coronavírus é ativado verbalmente no texto. Em acréscimo, nas imagens, são ativados os objetos de discurso máscara e Corona. O conjunto desses elementos é por meio de uma cognição distribuída entrelaçado na construção de sentidos do meme, na direção da ideia da relação entre Corona e coronavírus.

Em (11), encontra-se em primeiro plano a imagem da cerveja, que ativa o objeto de discurso Corona. Na legenda Essa é a única corona que eu quero pegar!, por um procedimento de retomada, reativa-se o objeto de discurso corona (o emprego do demonstrativo essa e a relevância da imagem no meme indicam a já ativação do objeto de discurso Corona), alvo do conteúdo expresso pelo verbo pegar. No meme, joga-se com o duplo sentido de corona (vírus ou cerveja?), indicando que haveria outra corona, haja vista a pressuposição operada pela adjetiva restritiva que eu quero pegar. Nesse meme, ainda que haja textualmente uma opção pela cerveja (não pelo vírus), o duplo sentido sugere a associação, o que em si representa depreciação da marca.

\section{CONSIDERAÇÕES FINAIS}

Neste artigo, analisamos um corpus de dez memes fotográficos cujo conteúdo versa sobre a relação entre a marca de cerveja Corona e o vírus/doença coronavírus/Covid-19. Nosso intuito foi compreender, pela ótica dos processos de referenciação, como os sujeitos constroem essa relação na elaboração dos memes e quais sentidos possíveis decorrem dela.

A análise demonstrou que nos memes a associação entre a cerveja Corona (do espanhol) e o coronavírus (do latim corona), pode decorrer do desconhecimento da semelhança formal dos nomes ou advir da intenção deliberada mesma de produzir humor.

Do ponto de vista da estrutura composicional dos memes, vários recursos formais foram adotados com o objetivo de relacionar os dois conteúdos, tais como a legendagem e a fotomontagem, técnicas a partir das quais os referentes textuais foram introduzidos nos textos ou sugeridos para ativação inferencial pelo leitor. Assim, em todos os memes observados, houve ativação textual-discursiva ou cognitivo-inferencial do objeto de discurso coronavírus. Quanto à atividade de interpretação, a diferença é que o leitor, no segundo caso, necessita integrar um conjunto de informações dispostas de forma não necessariamente linear, sendo preciso realizar uma cognição distribuída na (re)construção de sentidos na/a partir da materialidade multimodal dos memes.

Retomando o título do artigo em que se pergunta Cerveja ou vírus?, a análise dos memes evidenciou que a construção de sentidos em momento algum obteve viés de alternância (Corona ou vírus). Diferentemente disto, os conteúdos Corona e coronavírus foram intencionalmente amalgamados. Assim, tornou-se evidente, após o estudo, que a marca de cerveja Corona, ao virar meme, foi alvo de associações que nos textos construíram hipersignificações negativas (como contaminação e perigo), perpassadas por um tom jocoso de humor.

Por fim, não sobeja adicionar que o compartilhamento de memes, por ser uma ação de propagação de ideias na sociedade, exige, pois, responsabilidade, já que pode reforçar valores que exaltam ou destroem determinada imagem.

\section{REFERÊNCIAS}

APOTHÉLOZ, D; REICHLER-BEGUELIN, M. Construction de la reference et stratégies de désignation. In: BERRENDONNER, A; REICHLER-BÉGUELIN, M. (ed.). Du sintagme nominal aux objects-de-discours: SN complexes, nominalizations, anaphores. Neuchâtel: Institute de Linguistique de l'Université de Neuchâtel, 1995. p. 227-271.

BRASSAC, C; LARDON, S; LE BER, F; MONDADA, L; OSTY, P. Analyse de l'émergence de connaissances au cours d'un processos collectif. Re-catégorisations, reformulations, stabilisations. Revue d'anthropologie des connaissances. v. 2, n. 2, p. 267-289, 2008. 
CHAGAS, V. Breve tipologia dos memes. Revista Zum, n.14, p. 1-12, abr.2018.

DAWKINS, R. Ogene egoísta. São Paulo: Companhia das Letras, 2007.

FOLHA DE SÃO PAULO. Disponível em: https://www1.folha.uol.com.br/mercado/2020/01/coronavirus-leva-a-pico-de-buscase mencoes-a-cerveja-corona-no-google-e-no-twitter.shtml. Acesso em : 15 abr, 2020.

GOOGLE TRENDS. Disponível em: https://trends.google.com.br/trends/explore?q=cerveja\%20corona\%20v\%C3\%ADrus. Acesso em: 15 abr. 2020

KRESS, G; V. L., T. Reading images: the grammar of visual design. London: Routledge, 20

LIMA, A.C. Visual, coloquial, virtu@l: o uso da expressão gráfica na conversação em redes sociais. São Paulo: USP, 2014. 151f. Tese (Doutorado) - Programa de Pós-Graduação em Ciências da Comunicação, Escola de Comunicação e Artes/Universidade de São Paulo, São Paulo, 2014.

MARCUSCHI, L; KOCH, I. Estratégias de referenciação e progressão referencial na língua falada. In: ABAURRE, M; RODRIGUES, A. (org.). Gramática do Português Falado. v. VIII. Campinas, São Paulo: Editora da Unicamp, 2002. p.31-58.

MARCUSCHI, L. O léxico: lista, rede ou cognição social? In: NEGRI, L; FOLTRAN, M; OLIVEIRA, R. (org.). Sentido e significação: em torno da obra de Rodolfo Ilari. São Paulo: Contexto, 2004. p.263-284.

MARCUSCHI, L. Coerência e cognição contingenciada. In.: Cognição, linguagem e práticas interacionais. Rio de Janeiro: Lucerna, 2007. p. 13-30.

MONDADA, L. Verbalisation de l'espace et fabrication du savoir: Approche linguistique de la construction des objets de discours. Lausanne: Université de Lausanne, 1994.

MONDADA, L. Cognition et parole-em-interaction. Veredas: Revista de Estudos Linguísticos, v. 6. n. 1, p. 9-27, jan../jun. 2002.

MONDADA, L. Production du savoir et interactions multimodales. Une étude de la modélisation spatiale comme activité pratique située et incarnée. Revue d'anthropologie des connaissances. v. 2, n. 2, p. 219-266, 2008.

MONDADA, L; DUBOIS, D. Construção dos objetos de discurso e categorização: Uma abordagemdos processos de referenciação. In: CAVALCANTE M.M., RODRIGUES B. B; CIULLA A. (orgs). Referenciação. São Paulo: Contexto, 2003 [1995].p. 17-52.

OLIVEIRA, J. Por uma tipologia de memes da Internet. Entremeios, v. 13, p. 01-15, 2017.

OPAS. Disponível em: https://www.paho.org/bra/index.php?option=com content\&view=article\&id=6101:covid 19\&Itemid=875. Acesso em: 15 abr. 2020.

RECUERO, R. Memes em weblogs: proposta de uma taxionomia. Revista FAMECOS, Porto Alegre, n. 32, p. 23-31, abr. 2007.

ROJO, R; MOURA, E. Multiletramentos na escola (org.). São Paulo: Parábola Editorial, 2012. 
SHIFMAN, L. The cultural logic of photo-based meme genres. Journal of visual culture. v.13, n. 3, p. 340-358, 2014.

YOU GOV. Disponível em: https://today.yougov.com/topics/food/articles-reports/2020/02/26/first-it-was-joke-corona-beerreally-suffering-cor. Acesso em: 15 abr. 2020.

\section{() (1) $\circledast$}

